\title{
Spatial time-dependent reliability analysis of corrosion damage to RC structures with climate change
}

\section{Lizhengli Peng}

PhD student, Centre for Infrastructure Performance and Reliability, University of Newcastle, Callaghan, NSW, Australia
Mark G. Stewart

Professor and Director, Centre for Infrastructure Performance and

Reliability, University of Newcastle, Callaghan, NSW, Australia

The environment around concrete structures may be influenced by a changing climate, especially in the long run, leading to an acceleration of deterioration. Therefore, the safety, serviceability and durability of concrete infrastructure may decline at a faster rate than expected. Carbonation-induced deterioration to concrete structures constructed in Sydney, Australia and Kunming, China under a changing climate is investigated in this paper. Two emissions scenarios are considered - RCP 8.5 and RCP 4.5, representing high and medium greenhouse gas emissions scenarios respectively. The spatial time-dependent reliability analysis includes time-dependent climate scenarios and deterioration processes, as well as a large number of random variables and spatial random fields of material properties and dimensions. The surface of concrete structures is discretised into a large number of elements and the likelihood and extent of corrosion damage is calculated by tracking the evolution of the corrosion process of each element using Monte Carlo simulations. The results show that a changing climate could cause the extent of damage to increase by up to $6 \%$ for reinforced concrete infrastructure in Kunming. The findings may be used to assess climate adaptation measures in the design stage, as well as a cost-benefit analysis of climate adaptation measures.

\section{Notation}

$a$

binding capacity, defined as the amount of carbon dioxide $\left(\mathrm{g} / \mathrm{m}^{3}\right)$ needed for carbonation of the alkaline compounds contained in a unit volume of cementitious material

$C_{\mathrm{CaO}} \quad$ calcium oxide content in cement $(0 \cdot 65)$

$C_{\mathrm{CO} 2}(t) \quad$ time-dependent increase in atmospheric carbon dioxide concentration $\left(10^{-3} \mathrm{~kg} / \mathrm{m}^{3}\right)$

$C_{\mathrm{e}} \quad$ cement content $\left(\mathrm{kg} / \mathrm{m}^{3}\right)$

$D(t) \quad$ carbon dioxide diffusion coefficient in concrete calibrated for time period 2010 to $t$

$D_{\text {bar }}$

$D_{1}$

$d_{\text {crack }}(t)$

$d_{x}, d_{y}$

E

$E_{\mathrm{c}} \quad$ modulus of elasticity (MPa)

$f_{\mathrm{c}} \quad$ concrete compressive strength after 1 year (MPa)

$f_{\mathrm{c}}^{\prime} \quad$ concrete design compressive strength (MPa)

$f_{\mathrm{c}(28)} \quad$ 28-day in situ compressive strength (MPa)

$f_{d_{\text {crack }}}\left(d_{\text {crack }}, t\right)$ multi-dimensional probability distribution of $d_{\text {crack }}(t)$ obtained from Monte Carlo simulation analysis for each time step $t$

\section{$f_{\mathrm{e}}$}

$f_{\mathrm{RH}}(t)$

$f_{\mathrm{t}}$

$f_{\mathrm{T}}(t) \quad$ time-dependent change in diffusion coefficient due to changes in temperature

$g_{\mathrm{e}} \quad$ constant equal to $2 \cdot 5$

$i_{\text {corr-20 }}$ reference corrosion rate $\left(\mu \mathrm{A} / \mathrm{cm}^{2}\right)$, also written as $i_{\text {corr-ref }}$

$k_{\text {site }} \quad$ factor to account for increased carbon dioxide levels in non-remote environments

$M_{\text {Ca0 }} \quad$ molar mass of calcium oxide ( $=56 \mathrm{~g} / \mathrm{mol}$ )

$M_{\mathrm{CO} 2} \quad$ molar mass of carbon dioxide ( $\left.=44 \mathrm{~g} / \mathrm{mol}\right)$

$\mathrm{ME}\left(r_{\text {crack }}\right) \quad$ crack propagation model error

$n_{\mathrm{d}}$ age factor for carbon dioxide diffusion coefficient

$n_{\mathrm{m}}$

$R$

$\mathrm{RH}_{\mathrm{ref}}$

$T(t)$

$T_{\mathrm{i}}$

$T_{\mathrm{sev}}$

$T_{\mathrm{sp}}$

$T_{1 \text { st }}$ age factor for microclimatic conditions gas constant $(\mathrm{kJ} / \mathrm{mol} \mathrm{K})$ reference $\mathrm{RH}\left(=65 \%\right.$ at temperature of $\left.20^{\circ} \mathrm{C}\right)$ temperature $\left({ }^{\circ} \mathrm{C}\right)$ at time $t$ year when carbonation depth exceeds concrete cover

time for crack to develop from crack initiation to a limit crack width

time to corrosion damage

time to first cracking (hairline crack of $0.05 \mathrm{~mm}$ width) 
time, defined in calendar years starting from 2010 , assuming the building went into service in 2010

$t_{0}$ 1 year

$x_{\mathrm{c}}(t)$

$\alpha_{\mathrm{H}}$ carbonation depth at time $t(\mathrm{~mm})$ degree of hydration

element size

$\delta_{0} \quad$ thickness of porous zone $(\mu \mathrm{m})$

$\theta_{x}, \theta_{y} \quad$ scales of fluctuation for a 2D random field in $x$ and $y$ directions respectively

$\rho(\tau) \quad$ correlation function

$\sigma \quad$ standard deviation

$\tau_{x}, \tau_{y} \quad$ distances between centroid of elements $i$ and elements $j$ in the $x$ and $y$ directions respectively

\section{Introduction}

Maintaining reinforced concrete (RC) structures is a pressing challenge throughout the world. For RC structures, deterioration is attributed to the harsh environmental conditions that the structures encounter during their lifetimes. There are two major processes that cause corrosion of embedded steel - carbonation and chloride ion penetration. The quality and cover of concrete are critical to the initiation and sustenance of reinforcement corrosion. Once corrosion of reinforcement is initiated in an $\mathrm{RC}$ structure, it propagates, causing surface cracking and subsequent spalling of the cover concrete due to expansion of the corroding steel and resulting in inevitable damage to the structure (Fang and Yang, 2011; Malumbela et al., 2011; Melchers et al., 2006). Chlorideinduced corrosion of reinforcing bars is the primary cause of deterioration of $\mathrm{RC}$ structures in onshore and offshore marine environments, or areas that use de-icing salts during winter. In other locations, carbonation of concrete and associated corrosion of the embedded reinforcement is a threat to the durability of RC infrastructure. This is especially the case for many concrete structures in inland areas, where a significant concern is rebar depassivation caused by carbonation and a low design concrete cover (Wang and Qin, 2007). In this paper, carbonation-induced corrosion of the reinforcing steel in concrete structures is presented for inland locations in Australia and China.

The deterioration rate of RC structures depends on the construction processes employed and the composition of the materials used, as well as the environment. Increases in atmospheric carbon dioxide concentrations and temperature and changes in relative humidity $(\mathrm{RH})$ due to a changing climate will, especially in the long term, lead to an acceleration of deterioration and therefore a faster decline of the safety, serviceability and durability of concrete infrastructure. The fourth assessment report of the Intergovernmental Panel on Climate Change (IPCC) (IPCC, 2007) indicated a significant increase of carbon dioxide concentration in the atmosphere, from $280 \mathrm{ppm}$ in 1750 to $380 \mathrm{ppm}$ in 2005, with an increasing trend. The carbon dioxide concentration is projected to increase from $369 \mathrm{ppm}$ in 2000 to $936 \mathrm{ppm}$ after 100 years, yielding a range of temperature increases of $4 \cdot 0-6 \cdot 1^{\circ} \mathrm{C}$ by 2100 (Rogelj et al., 2012). Rising temperatures will increase rates of carbonation penetration, as well as the corrosion rate. For example, corrosion rates will increase by up to $15 \%$ for a temperature increase of only $2^{\circ} \mathrm{C}$ (Stewart et al., 2011, 2012). Concrete infrastructure in higher-temperature environments suffers more severe carbonation-induced corrosion (Roy et al., 1996).

There is some research reported on the effects of a changing climate on the deterioration of concrete structures. Talukdar et al. (2012) predicted carbonation depths in Canada for climate change scenarios, but did so using a deterministic model and assuming that RH is constant. Stewart et al. (2011, 2012) developed probabilistic and reliability-based methods to predict concrete deterioration under a changing climate in Australia. They showed that the additional carbonation-induced damage risk for the A1FI (high fossil-intensive) emissions scenario would be up to $16 \%$ higher if there are no changes to how concrete structures are designed or constructed. Stewart and Peng (2010) used a simplified deterioration model and global IPCC carbon dioxide concentration and temperature change data (IPCC, 2007) to conduct a life cycle cost assessment to assess the cost-effectiveness of increasing design concrete cover as an adaptation measure to mitigate the effects of carbonation of concrete. This preliminary analysis found that increasing design concrete cover may not be cost-effective, but the results were sensitive to repair and user disruption costs. However, these models relied on relatively straightforward time-dependent deterioration models, and ignored the effect of changes in RH on the deterioration process. Peng and Stewart (2014) improved the carbonation model by taking into account the effects of temperature and $\mathrm{RH}$ on diffusion coefficients and site-dependent carbon dioxide levels, considering RH as a time-dependent variable. It was found that climate change can cause an additional $7-20 \%$ of carbonation-induced damage by 2100 for RC buildings in temperate or cold regions of China.

Due to the spatial variability of workmanship, environment and other factors, it is recognised that the material and dimensional properties of concrete structures will not be homogeneous. Moreover, it is necessary to model the spatial variability of parameters in order to be able to characterise not only the probability of degradation but also the extent of damage (Darmawan and Stewart, 2007; Na et al., 2012; Papakonstantinou and Shinozuka, 2013; Stewart and Mullard, 2007; Sudret, 2008; Vu and Stewart, 2005). The extent of damage is an important variable that characterises damage to a structure and may be used for optimising maintenance strategies (Li et al., 2004; Mullard and Stewart, 2009, 2012; Stewart, 2006).

In this paper, spatial time-dependent reliability methods are employed, by considering the spatial variability of concrete material properties and concrete cover, to predict corrosion damage for RC slabs subject to carbonation-induced corrosion. Time-dependent RH effects on corrosion rate are also included. The two latest emissions scenarios - RCP (representative concentration pathway) 8.5 and RCP 4.5, which represent high and medium greenhouse gas emissions scenarios respectively - are 
considered. As case studies, RC buildings in the Australian city of Sydney and the Chinese city of Kunming were chosen. The spatial time-dependent reliability analysis includes the timedependent climate scenarios and deterioration processes, as well as a large number of random variables and spatial random fields of material properties and dimensions. The surface of concrete structures is discretised into a large number of elements and the likelihood and extent of corrosion damage is calculated by tracking the evolution of the corrosion process of each element using Monte Carlo simulation (MCS). The findings provide a basis for the development of climate adaptation through the design of concrete structures, as well as a cost-benefit analysis of adaptation measures. The analysis here is for ordinary Portland cement (OPC) concrete infrastructure, but can be extended for other types of concrete.

\section{A changing climate}

The IPCC fifth assessment report (IPCC, 2013) will use representative concentration pathways (RCPs). The four RCPs - RCP 2.6, RCP 4.5, RCP 6.0 and RCP 8.5 - are named after a possible range of radiative forcing values in the year $2100(2 \cdot 6,4 \cdot 5,6 \cdot 0$ and $8.5 \mathrm{~W} / \mathrm{m}^{2}$ respectively), and RCP 8.5 , RCP 6.0 and RCP 4.5 are roughly equivalent to $\mathrm{A} 1 \mathrm{FI}, \mathrm{A} 1 \mathrm{~B}$ and $\mathrm{A} 1 \mathrm{~B}$ to $\mathrm{B} 1$ emissions scenarios respectively (Inman, 2011). The scenarios RCP 8.5 and RCP 4.5, representing high and medium emissions scenarios respectively, are used in this study. An emissions scenario based on the 2010 carbon dioxide level of $389 \mathrm{ppm}$ is also considered to provide a reference for other emissions scenarios. Figure 1 shows the IPCC projection of the annual average carbon dioxide concentrations from 2010 (Meinshausen et al., 2011), but a more recent study (Peters et al., 2013) shows that current emissions are tracking slightly above RCP 8.5 . If this 'business as usual' trend continues, then it is likely that carbon dioxide concentrations will reach $1000 \mathrm{ppm}$ by the end of this century.

To project spatially dependent temperature increases in the future under different emissions scenarios, various climate models or

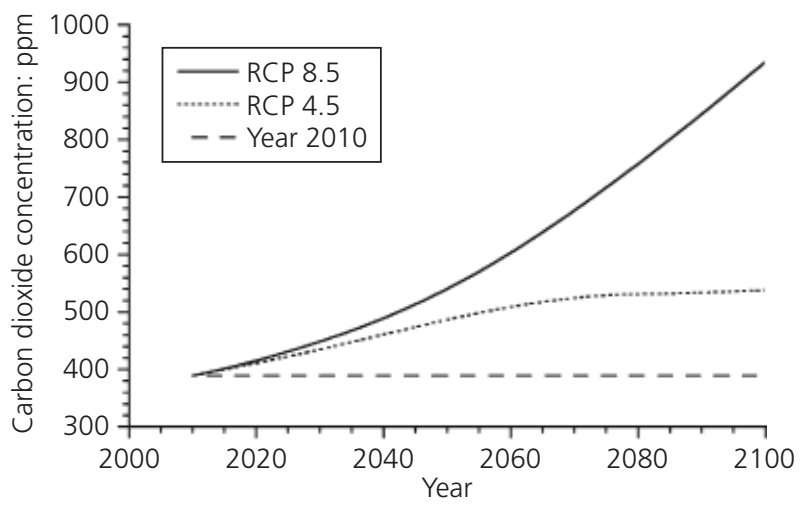

Figure 1. Projected global annual average carbon dioxide concentration for RCP 8.5, RCP 4.5 and year 2010 emissions scenarios from model Magicc atmosphere-ocean general circulation models (GCMs) have been developed based on physical principles at the continental scale. To find the full range of possible values, it is necessary to use multiple models to take into account the uncertainties of models in any impact assessment (Peng and Stewart, 2014). For this analysis the cities of Sydney (Australia) and Kunming (China) were selected; both are major urban centres. Six GCMs were used to project temperature and RH change from 2010 to 2100 for the two cities; for details see Peng and Stewart (2014). The projected annual average temperatures and RH for the six GCM projections, for RCP 8.5 and RCP 4.5 emissions scenarios for Sydney and Kunming, are shown in Figures 2 and 3 respectively. There is a large variability between model projections, which makes climate projections particularly challenging. On the other hand, the large variations could cover the full range of possible values. Clearly, temperature and RH projections for Sydney and Kunming are similar.

\section{Carbonation-induced corrosion}

\section{Carbonation penetration}

The carbonation penetration process is simulated as a diffusion process, considering a wide range of influencing parameters

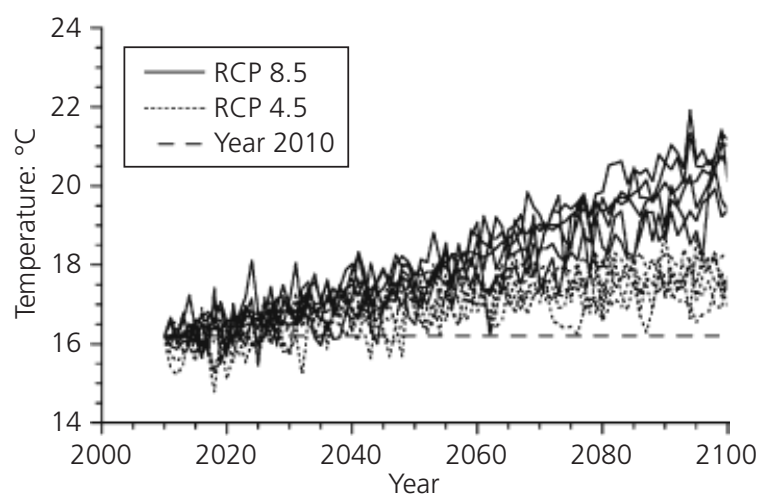

(a)

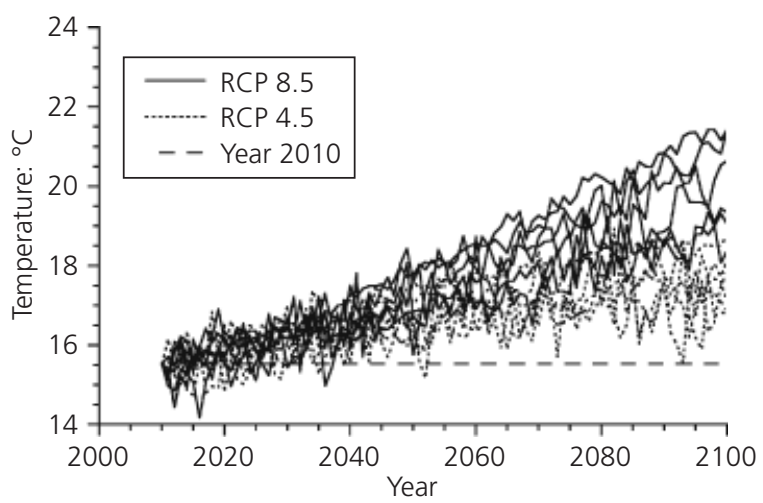

(b)

Figure 2. Projected annual average temperatures for the six GCM (BCC-CSM1.1, MIROC5, IPSL-CM5A-LR, CSIRO-MK3.6.0, CNRMCM5, ACCESS1.0) projections for RCP 8.5, RCP 4.5 and year 2010 emissions scenarios for (a) Sydney and (b) Kunming 


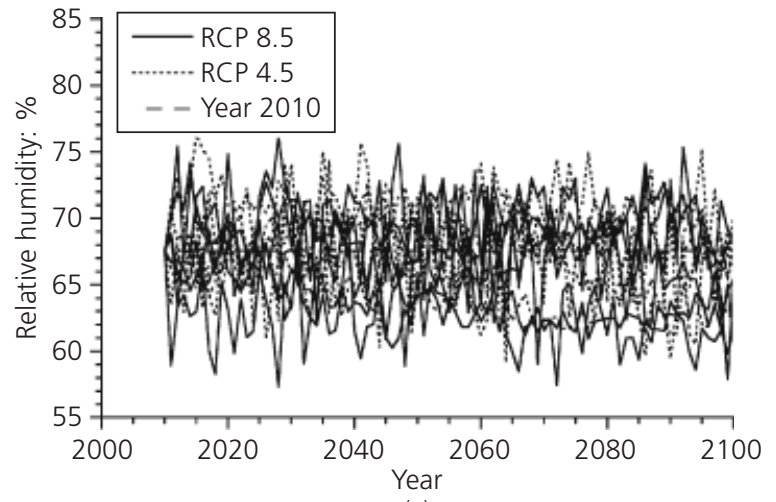

(a)

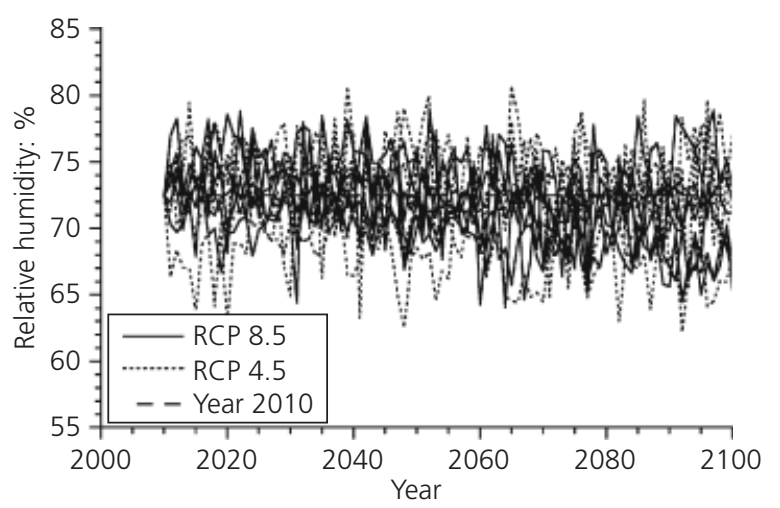

(b)

Figure 3. Projected annual average RH for the six GCM (BCCCSM1.1, MIROC5, IPSL-CM5A-LR, CSIRO-MK3.6.0, CNRM-CM5, ACCESS1.0) projections for RCP 8.5, RCP 4.5 and year 2010 emissions scenarios for (a) Sydney and (b) Kunming

(DuraCrete, 1998; Yoon et al., 2007). However, such models are point-in-time predictive models that assume carbon dioxide concentrations and diffusion coefficients are constant. Stewart et al. (2011) considered this phenomenon and calculated carbonation depths due to enhanced atmospheric carbon dioxide concentration conditions using the average carbon dioxide concentration over the time period, and not the peak value at time $t$. Peng and Stewart (2014) then considered the carbonation process as a steady-state process modelled by Fick's first law, and considered time-dependent carbon dioxide concentration, temperature and RH effects. The carbonation depth model is modified as

$$
\begin{aligned}
x_{\mathrm{c}}(t)= & {\left[\frac{2 D(t)}{a} \int_{2010}^{t} f_{\mathrm{T}}(t) f_{\mathrm{RH}}(t) k_{\mathrm{site}} C_{\mathrm{CO} 2}(t) \mathrm{d} t\right]^{1 / 2} } \\
& \times\left(\frac{t_{0}}{t-2009}\right)^{n_{\mathrm{m}}} t \geqslant 2010
\end{aligned}
$$$$
1 .
$$

2. $D(t)=D_{1}(t-2009)^{-n_{\mathrm{d}}}$ 3a. $a=0 \cdot 75 C_{\mathrm{e}} C_{\mathrm{CaO}} \alpha_{\mathrm{H}} \frac{M_{\mathrm{CO} 2}}{M_{\mathrm{CaO}}}$

3b. $\quad \alpha_{\mathrm{H}} \approx 1-\mathrm{e}^{-3 \cdot 38 \mathrm{w} / \mathrm{c}}$

where $t$ is defined in calendar years starting from 2010 (assuming the building went into service in year 2010), $x_{\mathrm{c}}(t)$ is the carbonation depth at time $t, C_{\mathrm{CO} 2}(t)$ is the time-dependent increase in atmospheric carbon dioxide concentration $\left(10^{-3} \mathrm{~kg} / \mathrm{m}^{3}\right)$ as shown in Figure 1 (using the conversion factor $1 \mathrm{ppm}=$ $\left.0.0019 \times 10^{-3} \mathrm{~kg} / \mathrm{m}^{3}\right), k_{\text {site }}$ is a factor to account for increased carbon dioxide levels in non-remote environments, $f_{\mathrm{T}}(t)$ is the time-dependent change in the diffusion coefficient due to changes in temperature, $f_{\mathrm{RH}}(t)$ is the time-dependent change in the diffusion coefficient due to changes in $\mathrm{RH}, D(t)$ is the carbon dioxide diffusion coefficient in concrete calibrated for time period 2010 to $t, D_{1}$ is the carbon dioxide diffusion coefficient at $t=2010, n_{\mathrm{d}}$ is the age factor for the carbon dioxide diffusion coefficient, $t_{0}$ is 1 year, $C_{\mathrm{e}}$ is the cement content $\left(\mathrm{kg} / \mathrm{m}^{3}\right), C_{\mathrm{CaO}}$ is the calcium oxide content in cement $(0 \cdot 65), \alpha_{\mathrm{H}}$ is the degree of hydration (the degree of hydration for OPC after more than $400 \mathrm{~d}$ is estimated as in Equation 3b (de Larrard, 1999)), $M_{\mathrm{CaO}}$ is the molar mass of calcium oxide $(=56 \mathrm{~g} / \mathrm{mol}), M_{\mathrm{CO} 2}$ is the molar mass of carbon dioxide $(=44 \mathrm{~g} / \mathrm{mol})$ and $\mathrm{w} / \mathrm{c}$ is the water/cement ratio. The age factor for microclimatic conditions $n_{\mathrm{m}}$ associated with the frequency of wetting and drying cycles is $n_{\mathrm{m}}=0$ for sheltered outdoor exposure and $n_{\mathrm{m}}=0 \cdot 12$ for unsheltered outdoor exposure.

The carbon dioxide concentrations predicted by the IPCC (Figure 1) are global means that are based on measurements collected at remote marine sea level locations such as Mauna Loa in Hawaii and Wisconsin in the Great Lakes region. However, the carbon dioxide level in urban, suburban and rural locations is usually higher than the global mean value because of anthropogenic and natural sources. The correction factor $k_{\text {site }}$ is used to convert global mean carbon dioxide concentration to local levels and the statistical parameters for $k_{\text {site }}$ are obtained from different regions in the world (Peng and Stewart, 2014).

The mean values for $D_{1}$ and $n_{\mathrm{d}}$ are given in Table 1 as a function of $\mathrm{w} / \mathrm{c}$ ratio; Yoon et al. (2007) provided estimates of maximum (95th percentile) values for $D_{1}$ and $n_{\mathrm{d}}$. The standard deviation for $D_{1}$ is approximately $0 \cdot 15$ and the coefficient of variation $(\mathrm{CoV})$ for $n_{\mathrm{d}}$ is approximately 0.12 for all $\mathrm{w} / \mathrm{c}$ ratios (Stewart et al., 2011). These statistics represent model error (or accuracy). These parameters are based on $T=20^{\circ} \mathrm{C}$ and $\mathrm{RH}=65 \%$.

A rise in temperature will increase the diffusion coefficient and hence the carbonation depth. The effect of temperature on the diffusion coefficient is modelled using the Arrhenius law (e.g. DuraCrete, 2000; Yoon et al., 2007), where the time-dependent 


\begin{tabular}{lcc}
\hline W/c ratio & $D_{1}: 10^{-4} \mathrm{~cm}^{2} / \mathrm{s}$ & $n_{\mathrm{d}}$ \\
\hline 0.45 & 0.65 & 0.218 \\
0.50 & 1.24 & 0.235 \\
0.55 & 2.22 & 0.240
\end{tabular}

Table 1. Mean parameter values (Yoon et al., 2007) (use linear interpolation for intermediate values)

change in diffusion coefficient when compared to a temperature of $20^{\circ} \mathrm{C}$ is

$$
\text { 4. } f_{\mathrm{T}}(t)=\exp \left\{\frac{E}{R}\left[\frac{1}{293 \cdot 15}-\frac{1}{273 \cdot 15+T(t)}\right]\right\}
$$

in which $T(t)$ is the temperature $\left({ }^{\circ} \mathrm{C}\right)$ at time $t, E$ is the activation energy of the diffusion process $(40 \mathrm{~kJ} / \mathrm{mol}$ (Kada-Benameur et al., 2000)) and $R$ is the gas constant $\left(8.314 \times 10^{-3} \mathrm{~kJ} / \mathrm{mol} \mathrm{K}\right)$. A $2^{\circ} \mathrm{C}$ temperature increase will increase the diffusion coefficient by $12 \%$.

The Model Code for Service Life Design (fib, 2006) recommends a model to take account of the influence of RH on the diffusion coefficient

$$
\text { 5. } f_{\mathrm{RH}}(t)= \begin{cases}0 & \mathrm{RH}(t) \leqslant 25 \% \\ {\left[\frac{1-(\mathrm{RH}(t) / 100)^{f_{\mathrm{e}}}}{1-\left(\mathrm{RH}_{\mathrm{ref}} / 100\right)^{f_{\mathrm{e}}}}\right]^{g_{\mathrm{e}}}} & \mathrm{RH}(t)>25 \%\end{cases}
$$

where $\mathrm{RH}_{\text {ref }}$ is the reference $\mathrm{RH}\left(=65 \%\right.$ at temperature $\left.=20^{\circ} \mathrm{C}\right)$, $f_{\mathrm{e}}$ is a constant $(=5 \cdot 0)$ and $g_{\mathrm{e}}$ is a constant $(=2 \cdot 5)$. The factor $f_{\mathrm{RH}}$ exceeds 1 when $\mathrm{RH}<65 \%$ and reduces to 0 when $\mathrm{RH}=100 \%$. Insufficient water is available for carbonation to commence for $\mathrm{RH} \leqslant 25 \%$ (Richardson, 1988), hence a lower limit of $\mathrm{RH}=25 \%$ is set. Carbonation tends to be highest for relative humidity $\mathrm{RH}(t)=50-70 \%$ (Russell et al., 2001), which is reflected in Equation 5.

\section{Corrosion propagation}

When the carbonation depth reaches the reinforcing bar, corrosion initiates at $T_{\mathrm{i}}$, where $T_{\mathrm{i}}$ is the year when the carbonation depth exceeds the concrete cover. The corrosion rate is variable and highly dependent on exposure conditions and atmospheric situations. Some empirical models exist, but each isolates only several variables (Raupach, 2006).

It is interesting to note that when water or oxygen is limited, the corrosion process may eventually stop. In fact, a very high humidity in concrete may reduce oxygen diffusion to the corrosion area and slow the corrosion process, while the shortage of water in dry concrete also reduces corrosion activities. The corrosion rate for carbonation or chlorides becomes negligible when $\mathrm{RH}(t)$ is less than about $50 \%$ (Gonzalez et al., 1980; Neville, 1995). The optimum RH for corrosion is $70-80 \%$, then the corrosion rate decreases as RH increases due to reduced diffusion of oxygen through the concrete (Neville, 1995). A model including $\mathrm{RH}$ and temperature effects on corrosion rate proposed by Breysse et al. (2013) shows that a lower RH will decrease the corrosion rate when $\mathrm{RH}$ is less than $\mathrm{RH}_{\text {ref }}$

$$
\begin{aligned}
& i_{\text {corr }}(\mathrm{RH}, T)=i_{\text {corr-ref }}\left(\mathrm{RH}_{\text {ref }}, T_{\text {ref }}\right) \\
& \times \exp \left[0 \cdot 0312\left(\mathrm{RH}-\mathrm{RH}_{\text {ref }}\right)\right] \\
& \text { 6. } \quad * \exp \left[-4736\left(\frac{1}{273 \cdot 15+T}-\frac{1}{273 \cdot 15+T_{\text {ref }}}\right)\right]
\end{aligned}
$$

where the reference state is $\mathrm{RH}_{\text {ref }}=80 \%$ and $T_{\text {ref }}=20^{\circ} \mathrm{C}$.

In the present study, the reference corrosion rate is denoted $i_{\text {corr-20 }}$ and is assumed to be log-normally distributed with statistical parameters given by DuraCrete (1998) (see Table 2, where a corrosion rate of $1 \mu \mathrm{A} / \mathrm{cm}^{2}=0.0116 \mathrm{~mm} /$ year). These values take into account the concrete grades suggested for the corresponding

Exposure class

$i_{\text {corr-20: } \mu \mathrm{A} / \mathrm{cm}^{2}}$

Mean Standard deviation Distribution

\begin{tabular}{llll}
\hline C1: dry & $0^{\mathrm{a}}$ & 0 & Log-normal \\
C2: wet or rarely dry (unsheltered) & 0.345 & 0.259 & Log-normal \\
C3: moderate humidity (sheltered) & 0.172 & 0.086 & Log-normal \\
C4: cyclic wet-dry (unsheltered) & 0.431 & 0.259 & Log-normal \\
\hline
\end{tabular}

assumed negligible $\left(=0 \cdot 1 \mu \mathrm{A} / \mathrm{cm}^{2}\right)$. 
exposure classes. Previous work (DuraCrete, 2000) indicates that the standard deviation in Table 2 does not include the variation caused by changes of $\mathrm{RH}$ and temperature; therefore, it is reasonable to consider their effects separately. The present analysis assumes a time-invariant corrosion rate for carbonation. This is likely to be a conservative assumption as the corrosion rate will generally decrease with time due to the build-up of rust products, thus impeding the corrosion process (e.g. Vu and Stewart, 2000).

\section{Time to crack initiation $\left(T_{1 \mathrm{st}}\right)$, severe cracking $\left(T_{\text {sev }}\right)$ and corrosion damage $\left(T_{\mathrm{sp}}\right)$}

After corrosion initiation time $T_{\mathrm{i}}$, reinforcing bars start to generate corrosion products. As there is a porous zone around the steel reinforcing bar, the corrosion products must first fill this zone before the products start to induce internal pressure on the surrounding concrete. Therefore, not all corrosion products contribute to the expansive pressure on the concrete. This approach to crack initiation ( $T_{1 \mathrm{st}}$, time to first hairline crack of $0.05 \mathrm{~mm}$ width) was used by El Maaddawy and Soudki (2007) and their model is used herein (for a review of crack initiation models, see Reale and O'Connor (2012)). The thickness of the porous zone $\left(\delta_{0}\right)$ is typically in the range $10-20 \mu \mathrm{m}$ and can be described using a normal distribution with a mean equal to $15 \mu \mathrm{m}$ and $\mathrm{CoV}$ of $0 \cdot 1$ (Stewart et al., 2011), which means there is $99.9 \%$ probability that $\delta_{0}$ is between 10 and $20 \mu \mathrm{m}$. It should be noted that the accuracy of the time to corrosion damage $T_{\mathrm{sp}}$ ( $\left.=T_{\mathrm{i}}+T_{1 \mathrm{st}}+T_{\mathrm{sev}}\right)$ is dominated by the accuracy of the time to corrosion initiation $T_{\mathrm{i}}$ and the time to crack propagation $T_{\mathrm{sev}}$ (i.e. the time for a crack to develop from crack initiation to a limit crack width of $w \mathrm{~mm}$ ), and so damage risk predictions are relatively insensitive to the crack initiation model (Stewart and Mullard, 2007).

The definition of how 'excessive' the crack width is depends on individual conditions and asset owner policies. In this paper, concrete structures are regarded as 'severely cracked' when the crack width reaches $1.0 \mathrm{~mm}$. Time-dependent crack widths were measured for different RC slabs based on experimental work (AlHarthy et al., 2011; Chernin et al., 2012; Mullard and Stewart, 2011). Mullard and Stewart (2011) modelled the rate of crack propagation, enabling the time for a crack to develop from crack initiation to a limit crack width to be determined. Since the corrosion rate is a time-dependent function of temperature and $\mathrm{RH}$, then the time to corrosion damage is corrected for a timevariant corrosion rate instead of a time-invariant (constant) corrosion rate (see Peng and Stewart (2014) for more details).

\section{Spatial time-dependent reliability model}

Reinforced concrete construction involves various processes including concrete batching, on-site dimensional set-out, reinforcement placement, compaction of the concrete and curing. The nature of these processes introduces the potential for substantial variability of concrete quality due to variations in work practices. The spatial variability of concrete cover, concrete strength, diffusion coefficient and binding capacity are included in the current analysis.

Random field theory can be used to model the spatial variability of these parameters. Therefore, an RC slab or surface can be represented by a $2 \mathrm{D}$ random field. In a random field, the surface is discretised into $k$ identical elements of size $\Delta$ and the random variables within the random field are statistically correlated based on the corresponding correlation function (Vanmarcke, 1983). The mid-point method is used to represent an element by the value at the centroid of that element and this value is assumed to be constant within the element.

The spatial correlation between elements in a random field can be described by a correlation function that defines the exact pattern of decay of the variance. The correlation function $\rho(\tau)$ determines the correlation coefficient between two elements separated by distance $\tau$ and is representative of the spatial correlation between the elements. As the distance between correlated elements becomes smaller, the correlation coefficient approaches unity as defined by the correlation function; likewise, as the distance increases, the correlation coefficient reduces.

The Gaussian correlation function has been widely used in engineering applications, including spatial modelling of RC structures, and as such it is used here to model the spatial correlation of elements within a random field (Der Kiureghian and Ke, 1988; Mullard and Stewart, 2009; Sudret, 2008). The Gaussian (or squared exponential) correlation function used here is

\section{7.}

$$
\rho(\tau)=\exp \left[-\left(\frac{\left|\tau_{x}\right|^{2}}{d_{x}^{2}}\right)-\left(\frac{\left|\tau_{y}\right|^{2}}{d_{y}^{2}}\right)\right]
$$

where $d_{x}=\theta_{x} / \pi^{1 / 2}$ and $d_{y}=\theta_{y} / \pi^{1 / 2}\left(\theta_{x}\right.$ and $\theta_{y}$ being the scales of fluctuation for a 2D random field in $x$ and $y$ directions respectively) and $\tau_{x}=x_{i}-x_{j}$ and $\tau_{y}=y_{i}-y_{j}$ are the distances between centroid of elements $i$ and $j$ in the $x$ and $y$ directions respectively. Once the stochastic random field is defined, MCS methods are used to generate random variables for each element and the spatially variable parameters of each element are then defined using the correlation function. MCS can also predict the deteriorated state of each element $\left(T_{\mathrm{i}}, T_{\mathrm{sp}}\right)$ at every time interval.

\section{Proportion of concrete surface subject to corrosion damage}

Corrosion damage is defined as the time when the concrete cover reaches a limit crack width of $1.0 \mathrm{~mm}$. Therefore, the percentage of the concrete surface suffering severe corrosion damage at time $t$ for each MCS realisation is

8. $d_{\text {crack }}(t)=\frac{n\left[t>T_{\mathrm{sp}(j)}\right]}{k} \times 100 \%$ 
where $T_{\mathrm{sp}(j)}$ is the time to corrosion damage of element $j$ and $n$ [ ] denotes the number of elements for which $t>T_{\mathrm{sp}(j)}$.

\section{Probability that at least $x \%$ of concrete surface is} damaged

The probability that at least $x \%$ of the concrete surface has damage at time $t$ is

9. $\operatorname{Pr}\left[d_{\text {crack }}(t) \geqslant x \%\right]=\int_{x \%}^{100 \%} f_{d_{\text {crack }}}\left(d_{\text {crack }}, t\right) \mathrm{d} d_{\text {crack }}$

where $f_{d_{\text {crack }}}\left(d_{\text {crack }}, t\right)$ is the multi-dimensional probability distribution of $d_{\text {crack }}(t)$ obtained from MCS analysis for each time step $t$. A value of $d_{\text {crack }}(t)$ is calculated and after many simulations the probability distribution $f_{d_{\text {crack }}}\left(d_{\text {crack }}, t\right)$ for every combination of $t$ and $d_{\text {crack }}(t)$ will be inferred. As will be shown later, $f_{d_{\text {crack }}}\left(d_{\text {crack }}, t\right)$ is highly non-Gaussian and so percentile values of $f_{d_{\text {crack }}}\left(d_{\text {crack }}, t\right)$ can only be predicted from simulation methods (Stewart and Mullard, 2007).

\section{Case study: RC slab}

\section{Structural configuration}

According to national code requirements, concrete cover requirements and concrete properties are not constant. Generally, codes require concrete covers ranging from $15 \mathrm{~mm}$ to $50 \mathrm{~mm}$ depending on the grade of concrete and the exposure class. Environmental exposure in Australia is classified by the concrete structures code AS 3600-2009 (Standards Australia, 2009) as three climatic zones (arid, temperate and tropical). Similarly, environmental exposures in China are also classified for three climatic areas as severe cold area, cold area and temperate area (MoCPRC, 2010; Peng and Stewart, 2014). The selected sites of Sydney and Kunming represent temperate climates in both codes. Because temperate climate zones have large population densities, the results can be typical for most RC buildings in both countries. The microclimate, on the other hand, concerns local conditions such as 'above ground', 'in-ground' and 'maritime' or, more specifically, the position of structural elements in relation to the fluctuating water level (and the time such elements remain dry) and the level of sulfates, $\mathrm{pH}$ and chlorides in the water or soil. To simplify the problem, an RC slab in a concrete structure located $50 \mathrm{~km}$ from the coast is studied in this paper (i.e. an outer suburb of Sydney). The results for RC slabs can be applied to roofs, floors, panels and walls, etc. Note that RC structures are assumed to use OPC concrete and standard formwork and compaction.

Concrete inside buildings in a dry environment, concrete surfaces subject to long-term rain in unsheltered exposures and $\mathrm{RC}$ permanently submerged in water generally have a low carbonation rate. However, concrete inside buildings with moderate air humidity and external concrete sheltered from rain have a higher likelihood of carbonation (Peng and Stewart, 2014). After corrosion is initiated, more humid exposure increases corrosion propagation. Therefore, the spatial time-dependent reliability analysis to follow will focus on corrosion predictions for sheltered and unsheltered RC slabs. It should be noted that RC buildings without air conditioning (e.g. warehouses and factories) are more critical due to their exposure to environmental changes.

The durability design requirements specified in AS 3600-2009 (Standards Australia, 2009) and GB 50010-2010 (MoCPRC, 2010) relate to minimum concrete cover and concrete compressive strength, and assume standard formwork and compaction. The durability requirements for an RC slab in buildings in Sydney and Kunming are shown in Table 3. The exposure classification conditions are given in AS 3600-2009, GB 500102010 and Peng and Stewart (2014). For RC structures in Sydney located $50 \mathrm{~km}$ from the coast, exposure A2 is appropriate for both sheltered and unsheltered environments (RC structures close to the coast in Sydney have higher cover and are not susceptible to carbonation-induced corrosion). The exposure classifications for RC slabs in the inland city of Kunming are exposures I and IIa for sheltered and unsheltered environments respectively. The reference corrosion rate for sheltered slabs is $\mathrm{C} 3$, and $\mathrm{C} 4$ for unsheltered slabs (see Table 2). On the other hand, the age factor for microclimate conditions $n_{\mathrm{m}}$ in Equation 1 is 0.12 for unsheltered outdoor exposures instead of zero for sheltered exposures. Note that the concrete compressive strengths in Chinese standards are based on cube compressive strengths. The bar diameter $D_{\text {bar }}$ is assumed to be $12 \mathrm{~mm}$; of course, in practice,

\begin{tabular}{lccccccc} 
Class & $\begin{array}{c}\mathrm{w} / \mathrm{c} \\
\text { ratio }\end{array}$ & $C_{\mathrm{e}}: \mathrm{kg} / \mathrm{m}^{3 a}$ & Mean $D_{1}$ & Mean $n_{\mathrm{d}}$ & $D_{\text {bar: }} \mathrm{mm}$ & Cover: $\mathrm{mm}$ & $f_{\mathrm{c}}^{\prime}: \mathrm{MPa}^{\mathrm{b}}$ \\
\hline A2 & 0.56 & 320 & 2.22 & 0.240 & 12 & 30 & 25 \\
I & 0.60 & 225 & 2.65 & 0.242 & 12 & 20 & $\mathrm{C} 20$ \\
Ila & 0.55 & 250 & 2.22 & 0.240 & 12 & 25 & $\mathrm{C} 25$ \\
\hline
\end{tabular}

a From AS 5100.5 (Standards Australia, 2004), GB50010-2002 (MoCPRC, 2002).

${ }^{b}$ C20 and C25 are cube compressive strength. 
$D_{\text {bar }}$ can take other values, but corrosion damage risks are not sensitive to bar diameter (Peng and Stewart, 2014).

\section{Spatial and stochastic variables}

A 2D random field is applied to the $\mathrm{RC}$ slabs considering the spatial variability of concrete cover, concrete strength, carbon dioxide diffusion coefficient and binding capacity. Because of self-weight effects in the construction process, the mean value of concrete compressive strength may vary with height in a column (Zhu et al., 2001). For RC slabs used for floors or roofs, or precast slabs, the height in the construction process is relatively small compared to the column height; height impacts on concrete strength can thus be ignored. However, for cast-in-situ walls, panels and columns, concrete strength may change in height (Shi and Stewart, 2014). Height impacts are not considered in this study and therefore the four parameters listed are modelled as stationary random fields with respect to space. Random and spatial variables modelled as non-stationary can be included in the analysis if more realistic structural configurations are to be modelled.

Data with which to characterise the spatial correlation of concrete dimensional, material property and corrosion parameters are limited ( $\mathrm{Na}$ et al., 2012; Stewart and Mullard, 2007; Sudret, 2008). The scale of fluctuation $\theta$ defines the distance over which correlation persists in a random field. Vanmarcke (1983) proposed various methods for the calculation of the scale of fluctuation for stationary random fields. These methods, however, require large amounts of spatial data and, although this information has been collected in some cases, the scale of fluctuation is typically estimated using engineering judgement. O'Connor and Kenshel (2013) estimated the scale of fluctuation of chloride surface concentration and the diffusion coefficient of chloride ions from field work on an ageing RC bridge structure located in a marine environment in Ireland. The scales of fluctuation for the two investigated deterioration variables were found to be 1.5-5.0 times higher than previously reported. However, due to a scarcity of reliable field data of concrete cover, concrete compressive strength, carbon dioxide diffusion coefficient and binding capacity, the scales of fluctuation in the $x$ and $y$ directions $\left(\theta_{x}\right.$ and $\left.\theta_{y}\right)$ are estimated based on previous studies, as summarised in Table 4 ( $\mathrm{Na}$ et al., 2012; Sudret, 2008). Because the scales of fluctuation are not identical, the four random fields need to be generated separately. Stewart and Mullard (2007) found that chloride-induced corrosion damage probabilities are not overly sensitive if the scale of fluctuation varies from $1.0 \mathrm{~m}$ to $3.0 \mathrm{~m}$ for concrete cover. Nonetheless, more effort is needed to characterise the scale of fluctuation, as well as the shape of the correlation function, with more confidence.

The size of the discretised element is usually defined based on practical and analytical considerations. Sterritt et al. (2001) suggested that the element size should be in the range $0 \cdot 10$ $0.75 \mathrm{~m}$. Therefore, an element size $\Delta=0.5 \mathrm{~m}$ is chosen here. The $\mathrm{RC}$ slab is $6 \mathrm{~m}$ long and $6 \mathrm{~m}$ wide, providing a total area of $36 \mathrm{~m}^{2}$. The results for RC slabs can be applied to roofs, floors, façade panels, balconies, walls etc., but with an adjustment in size.

To account for the random variation of basic parameters in structural analysis, a statistical description of the variability of material properties of RC slabs is required (see Table 5). Concrete strength is time-variant, and the time-dependent increase in concrete compressive strength after 1 year using the ACI method (Stewart, 1996) is $f_{\mathrm{c}}=1 \cdot 162 f_{\mathrm{c}(28)}$ where $f_{\mathrm{c}(28)}$ is the 28 -day in situ compressive strength. Time-dependent gains in strength beyond 1 year are not considered in the present analysis. Because the difference between cast-in-situ and precast concrete compressive strength is minor (Wiśniewski et al., 2012), the compressive strength statistics are assumed to be the same for cast-in-situ and precast concrete in this study. The statistics of concrete cover are based on Australian and Chinese field surveys (McGee, 1999; RGRRCSM, 1985), and the results are also listed in Table 5.

\section{Results}

To demonstrate the spatially distributed carbonation-induced corrosion progress on a $2 \mathrm{D}$ surface, the carbonation depth, time to corrosion initiation $T_{\mathrm{i}}$, time to first cracking $T_{1 \mathrm{st}}$ and time to severe corrosion damage $T_{\mathrm{sp}}$ of each element were calculated. Figure 4 shows three typical MCS realisations. The areas where corrosion was initiated, cracking was initiated and severe corrosion damage occurred is demonstrated every 10 years after 2070 . Each realisation shows a quite different corrosion progression in time and space. It also shows the clustering of damage. For the spatial time-dependent reliability analysis, the results such as proportion of surface corrosion damage were calculated at each time step for 10000 simulation runs. The figures now discussed show the statistics of the MCSs.

The mean carbonation depths of sheltered and unsheltered RC slabs in Sydney and Kunming are shown in Figure 5 based on the

\begin{tabular}{llllc}
\hline Parameter & Distribution & Mean & CoV & $\theta: \mathrm{m}$ \\
\hline Concrete cover & Truncated normal & Table 5 & Table 5 & 2 \\
Concrete strength $f_{\mathrm{c}(28)}$ & Truncated normal & Table 5 & Table 5 & 1 \\
Diffusion coefficient $D_{1}$ & Log-normal & Table 3 & $\sigma=0.15$ & 2 \\
Binding capacity a & Log-normal & Equation 3a & 0.30 & 2
\end{tabular}

Table 4. Random field parameters 


\begin{tabular}{|c|c|c|c|c|}
\hline Parameter & Mean & $\mathrm{CoV}$ & Distribution & Reference \\
\hline \multicolumn{5}{|l|}{ Concrete cover } \\
\hline Australia: cast in situ & $C_{n o m}+6 \mathrm{~mm}$ & $\sigma=11.5 \mathrm{~mm}$ & Truncated normal $^{a}$ & McGee (1999) \\
\hline Australia: precast & $C_{n o m}+3 \mathrm{~mm}$ & $\sigma=9.7 \mathrm{~mm}$ & Truncated normal ${ }^{a}$ & McGee (1999) \\
\hline China: cast in situ & $0.90 C_{\text {nom }}$ & $0 \cdot 300$ & Truncated normal $^{a}$ & RGRRCSM (1985) \\
\hline China: precast & $1 \cdot 30 C_{\text {nom }}$ & $0 \cdot 250$ & Truncated normal ${ }^{a}$ & RGRRCSM (1985) \\
\hline \multicolumn{5}{|l|}{$f_{\mathrm{c}(28)}$} \\
\hline Australia: 25 & $1.05 f_{c}^{\prime}$ & $0 \cdot 156$ & Truncated normal ${ }^{b}$ & Foster et al. (2013) \\
\hline China: C20 & $0.98 f_{c}^{\prime}$ & $0 \cdot 221$ & Truncated normal $^{b}$ & Peng and Stewart (2014) \\
\hline China: C25 & $0.90 f_{c}^{\prime}$ & $0 \cdot 196$ & Truncated normal ${ }^{b}$ & Peng and Stewart (2014) \\
\hline$f_{\mathrm{t}}$ & $0.53\left(f_{c}\right)^{1 / 2}$ & $0 \cdot 13$ & Normal & Mirza and Hatzinikolas (1979) \\
\hline$E_{\mathrm{c}}$ & $4600\left(f_{\mathrm{c}}\right)^{1 / 2}$ & $0 \cdot 12$ & Normal & Mirza and Hatzinikolas (1979) \\
\hline$n_{\mathrm{d}}$ & $0 \cdot 242$ & $0 \cdot 12$ & Normal & Stewart et al. (2011) \\
\hline $\operatorname{ME}\left(r_{\text {crack }}\right)$ & $1 \cdot 04$ & 0.09 & Normal & Mullard and Stewart (2011) \\
\hline$\delta_{0}$ & $15 \mu \mathrm{m}$ & $0 \cdot 1$ & Normal & Stewart et al. (2011) \\
\hline$k_{\text {site }}$ & & & & Peng and Stewart (2014) \\
\hline Urban area & $1 \cdot 14$ & 0.08 & Truncated normal ${ }^{\mathrm{C}}$ & Peng and Stewart (2014) \\
\hline Suburban area & 1.07 & 0.06 & Truncated normal ${ }^{\mathrm{C}}$ & Peng and Stewart (2014) \\
\hline Rural area & 1.05 & 0.04 & Truncated normal ${ }^{\mathrm{C}}$ & Peng and Stewart (2014) \\
\hline
\end{tabular}

\footnotetext{
a Truncated at $8 \mathrm{~mm}$.

b Truncated at $0 \mathrm{MPa}$.

c Truncated at $1 \cdot 0$.
}

Table 5. Statistical parameters for corrosion parameters, material properties and dimensions

average of six GCM projections. Precast and cast-in-situ RC slabs have the same mean carbonation depth. For unsheltered outdoor exposures, the age factor for microclimate conditions $n_{\mathrm{m}}$ is $0 \cdot 12$, hence the mean carbonation depths for unsheltered slabs are reduced significantly. Furthermore, exposure classification IIa is applied to unsheltered slabs in Kunming, and so this higher design requirement for unsheltered structural members reduces the carbonation depth further.

Even though the trend of temperature and $\mathrm{RH}$ projections for Sydney and Kunming are similar, the variations are quite different, and the variability of six GCM projections models is also large; therefore, simulations were run separately based on each GCM projection model. The effect of six GCM temperature and $\mathrm{RH}$ projections on the proportion of surface corrosion damage is shown in Figure 6, for emissions scenario RCP 8.5 and cast-insitu sheltered RC slabs in Kunming. There is only a $1.5 \%$ difference between maximum and minimum predicted proportions of surface corrosion damage, which is a quite low variability. Therefore, it is reasonable to present the average of the simulation results of six GCMs.

Figure 7 shows the mean proportion of surface corrosion damage for RC slabs in Sydney and Kunming for all emissions scenarios. The RC slabs in Kunming experience more severe corrosion damage than RC slabs in Sydney. For instance, the proportion of surface corrosion damage for cast-in-situ sheltered RC slabs in Kunming (Figure 7(e)) is about ten times higher than those in Sydney (Figure 7(a)). Regardless of sheltered or unsheltered exposures and cast-in-situ or precast construction methods, for $\mathrm{RC}$ structures in Sydney it is likely that about $1 \%$ of RC surfaces will be damaged by 2100 (see Figures 7(a)-7(d)). On the other hand, the proportion of surface corrosion damage for RC slabs in Kunming is reduced significantly from $16 \%$ for sheltered cast-insitu slabs (Figure $7(\mathrm{e})$ ) to less than $5 \%$ for unsheltered or precast slabs (Figures $7(\mathrm{f})$ and $7(\mathrm{~g})$ respectively). This is due to the higher durability requirements for unsheltered members (exposure IIa) than sheltered members (exposure I) in China and the fact that the concrete cover of the precast slabs in China had a higher mean and less $\mathrm{CoV}$ than cast-in-situ slabs. Therefore, the corrosion damage risks for precast unsheltered RC slabs in Kunming are negligible (Figure 7(h)). For the reasons listed above, only the results of cast in situ RC slabs are presented for further consideration.

Climate change may cause more severe corrosion damage. Compared to the reference year 2010 emissions scenario, RCP 8.5 and RCP 4.5 emissions scenarios can cause the extent of damage to increase by $0 \cdot 3-0 \cdot 6 \%$ and $3 \cdot 8-6 \cdot 1 \%$ for cast-in-situ sheltered RC slabs in Sydney and Kunming respectively (see Figures 7(a) and $7(\mathrm{e})$ ). In practical terms, this is equivalent to expecting that up to an additional $6 \%$ of all concrete surfaces by 2100 will be 
Magazine of Concrete Research

Volume 66 Issue 22
Spatial time-dependent reliability analysis of corrosion damage to RC structures with

climate change

Peng and Stewart

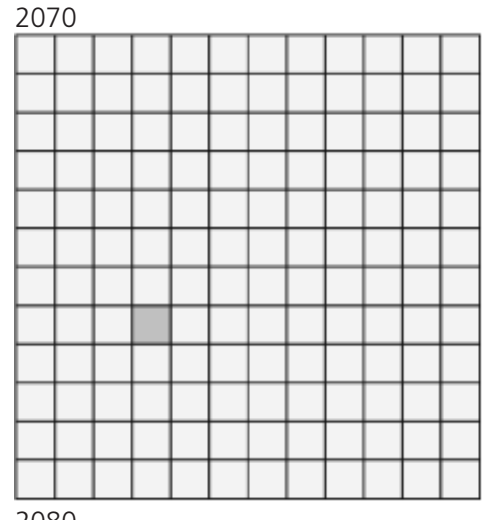

2080
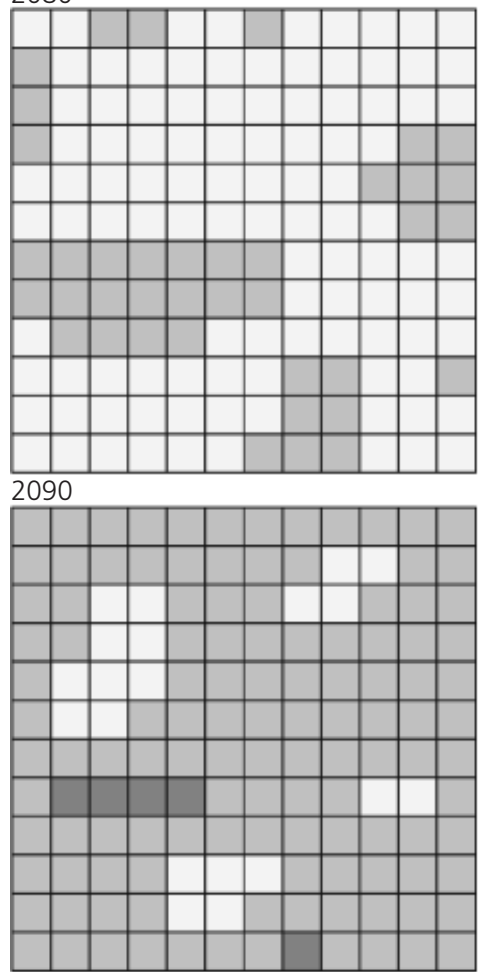

2100

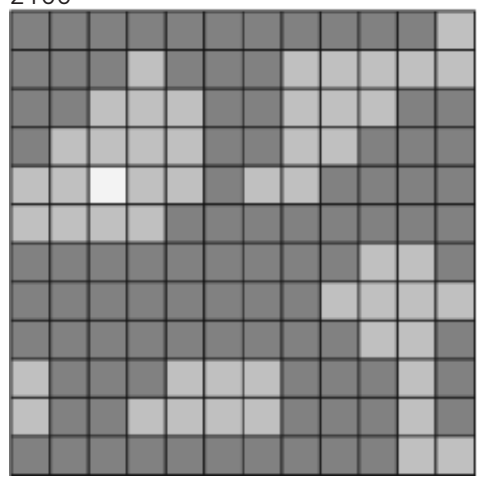

(a)

$\square$ Corrosion not initiated
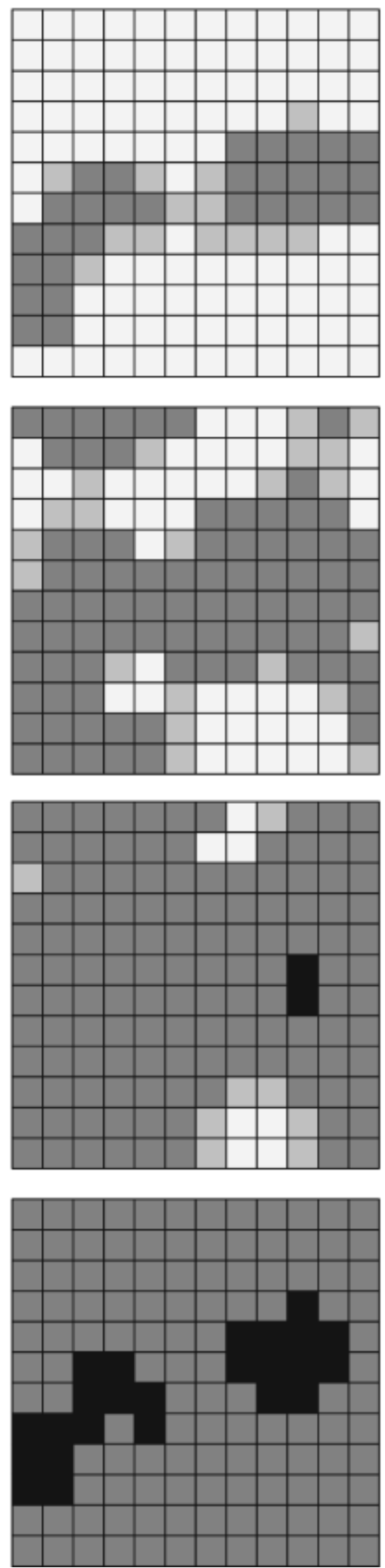

(b)

$\square$ Crack initiated
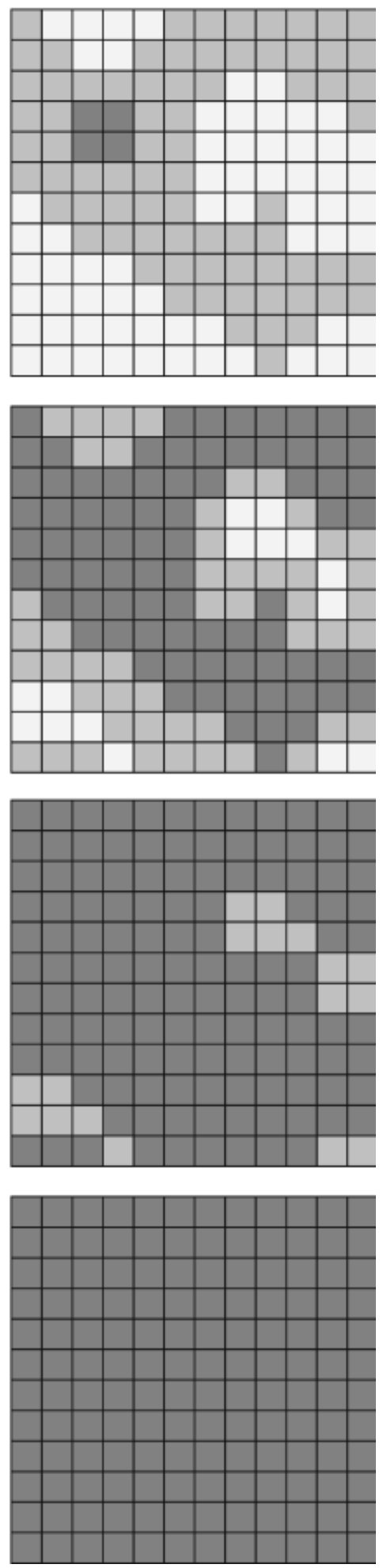

(c)

Severe corrosion damage

Figure 4. Simulation of spatially distributed corrosion process

showing three typical MCS realisations, (a), (b) and (c), for cast-

in-situ sheltered RC slab in Kunming under emissions scenario

RCP 8.5 


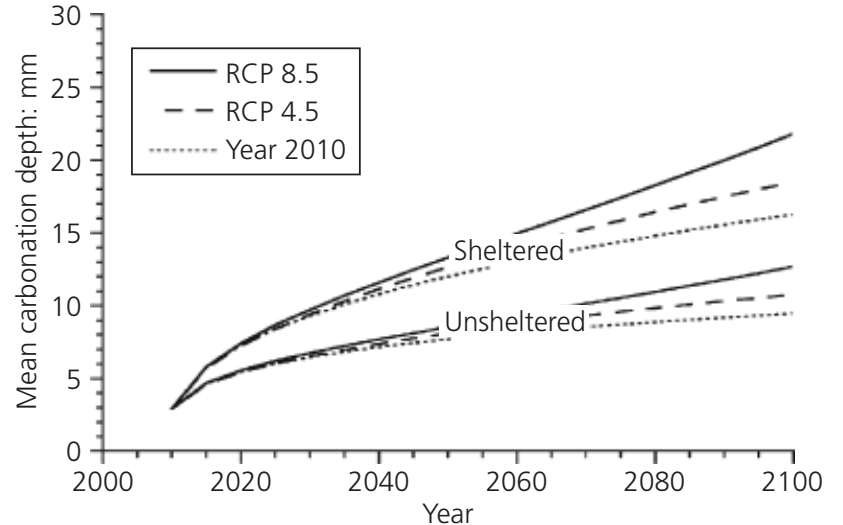

(a)

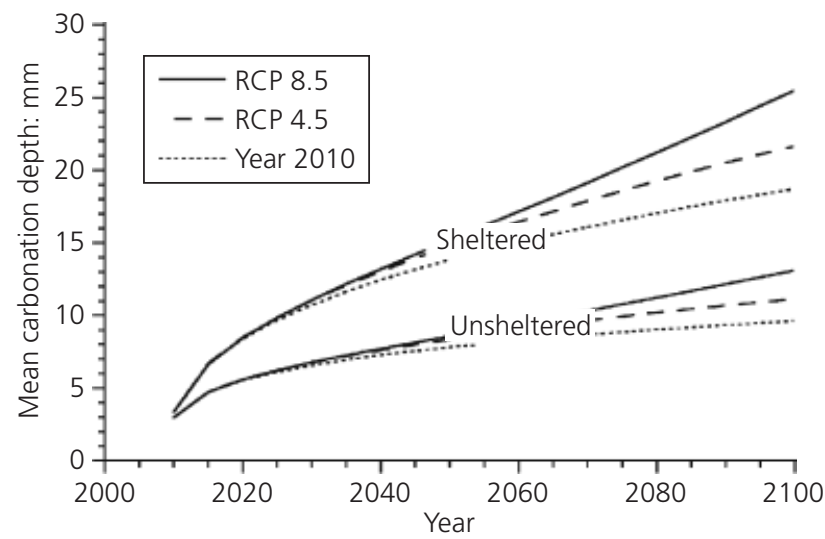

(b)

Figure 5. Mean carbonation depth for RCP 8.5, RCP 4.5 and year 2010 emissions scenarios for (a) Sydney and (b) Kunming

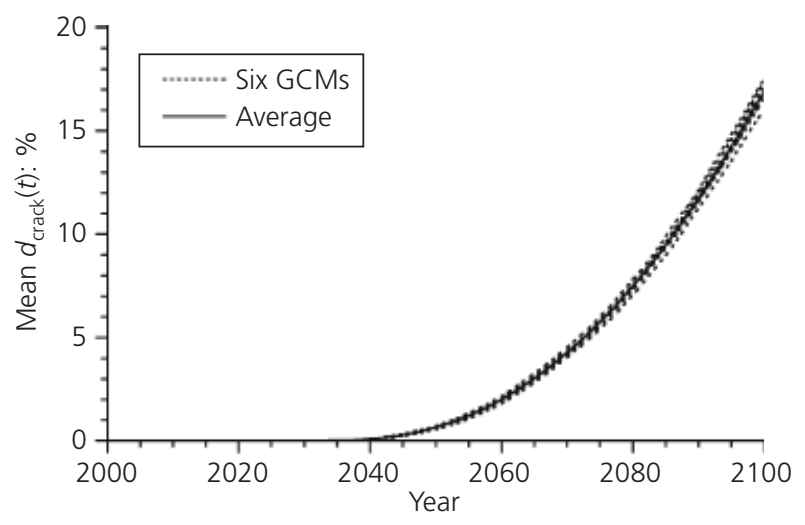

Figure 6. Mean proportion of surface corrosion damage for each GCM and the average for cast-in-situ sheltered RC slabs in Kunming under the RCP 8.5 emissions scenario

damaged and in need of maintenance or repair because of a changing climate. Climate change impacts will vary widely with location, environmental exposure and material design. For example, the additional mean corrosion damage caused by climate change for RC slabs in Xiamen (China) could be as high as 20\% (Peng and Stewart, 2014; Stewart et al., 2011, 2012). Previous non-spatial results of the mean proportion of surface corrosion damage for cast-in-situ sheltered RC slabs in Kunming are 25\% (Peng and Stewart, 2014) while the present spatial modelling predicts $17 \%$. The difference is mainly due to two reasons. The first is the effect of $\mathrm{RH}$ on the corrosion rate: the newly introduced corrosion rate model that considers both temperature and RH effects on the corrosion rate reduces the corrosion damage risk. The second reason is that this modelling introduced an additional random variable, the binding capacity $a$.

Figure 8 shows histograms of the proportion of surface corrosion damage for cast-in-situ sheltered RC slabs in Kunming in years 2040, 2070 and 2100 for RCP 4.5. It can be seen that $f_{d_{\text {crack }}}\left(d_{\text {crack }}, t\right)$ is highly non-Gaussian. The likelihood of no or little damage is significantly high, but will decrease with time. After 90 years (2100), the probability of significant damage is still low. Histograms of the proportion of surface corrosion damage for other slabs and other emissions scenarios showed similar trends.

Results from the spatial time-dependent reliability analysis can be shown as probability contours (Figure 9). Each probability contour represents the probability that at least $x \%$ of the concrete surface is damaged, as given by Equation 9. Figure 9 shows the results of cast-in-situ sheltered slabs in Sydney and Kunming, and there is little difference between the results for RCP 8.5 and RCP 4.5 emissions scenarios. However, compared to the reference year 2010 scenario, RCP 8.5 and RCP 4.5 scenarios cause the highest $(0.05$ probability contour) proportion of surface corrosion damage to increase by $0 \cdot 7-1 \cdot 6 \%$ and $9 \cdot 7-16 \cdot 3 \%$ for cast-in-situ sheltered RC slabs in Sydney and Kunming respectively. Likewise, for the $50 \%$ probability contour, RCP 8.5 and RCP 4.5 could lead to a $3 \cdot 6-5 \cdot 2 \%$ increase in the proportion of surface corrosion damage for cast-in-situ sheltered RC slabs in Kunming.

The probability contours may also be used to predict the time to first repair. The probability of severe corrosion damage for any repair threshold can be represented by $\operatorname{Pr}\left(d_{\text {crack }}(t) \geqslant X_{\text {repair }}\right)$. A review of the literature shows that the repair threshold $X_{\text {repair }}$ ranges from $0 \cdot 5$ to $5 \cdot 0 \%$ for a patch repair and 12 to $20 \%$ for complete replacement (e.g. Mullard and Stewart, 2012). For example, for $X_{\text {repair }}=5 \%$, there is a $50 \%$ probability that the first repair will occur between 2050 and 2091 (probability of occurrence between 0.05 and 0.55 ) for cast-in-situ sheltered slabs in Kunming under the RCP 8.5 emissions scenario (see Figure 9). Selecting a more stringent repair threshold $\left(X_{\text {repair }}=1 \%\right)$ will shorten repair actions by at least 6 years. There is a $5 \%$ chance that the first repair for cast-in-situ sheltered slabs in Kunming under RCP 8.5 could occur as soon as 2045 and 2050 for repair thresholds of $1 \%$ and $5 \%$ respectively. For RC slabs in Sydney, the $5 \%$ probability of first repair will occur significantly later than at Kunming. 


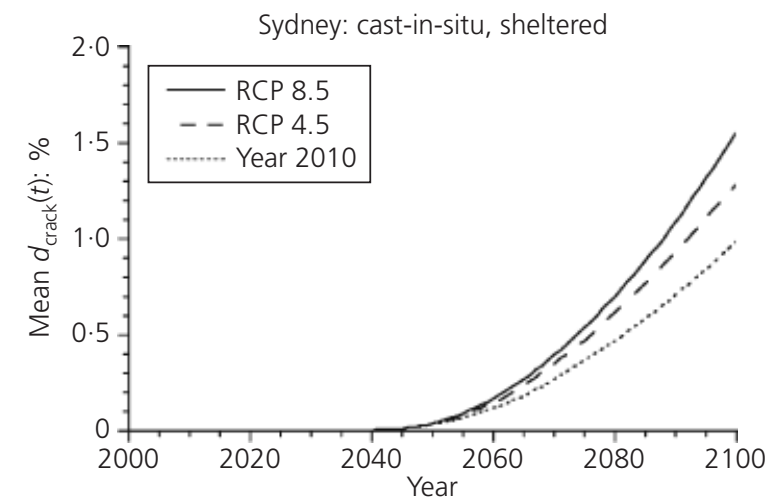

(a)

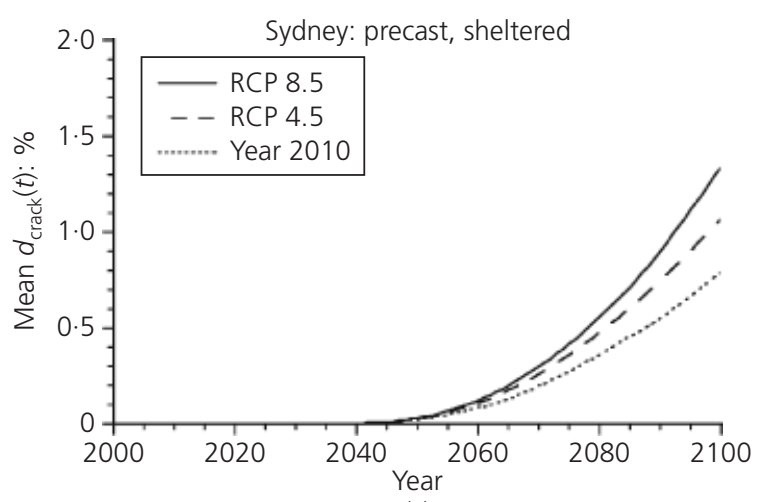

(c)

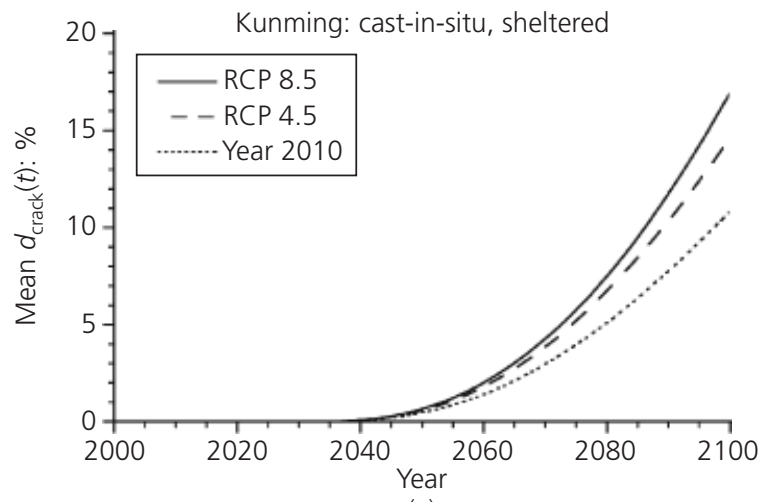

(e)

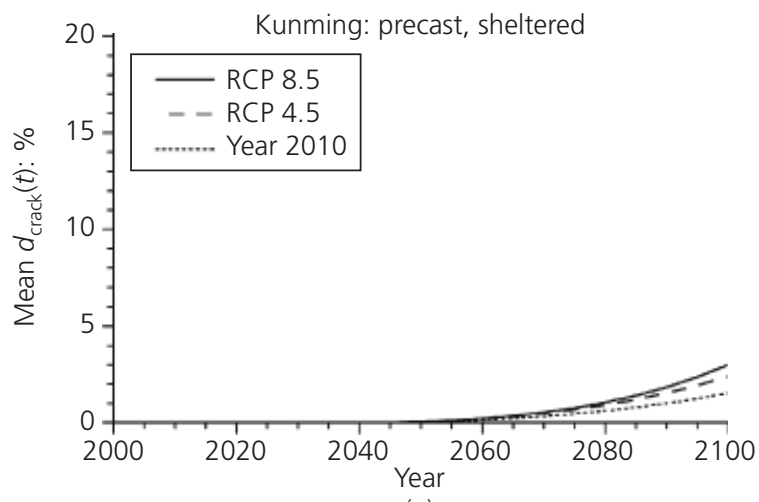

(g)

Figure 7. Mean proportion of surface corrosion damage for RCP 8.5, RCP 4.5 and year 2010 emissions scenarios for Sydney and Kunming.

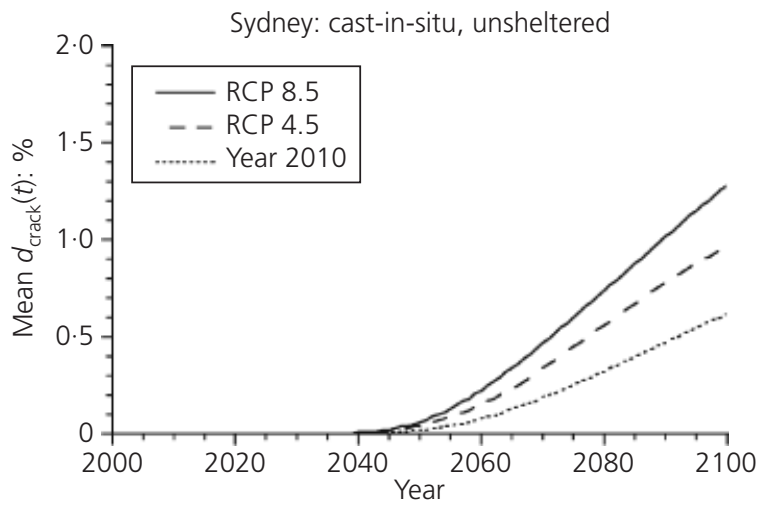

(b)

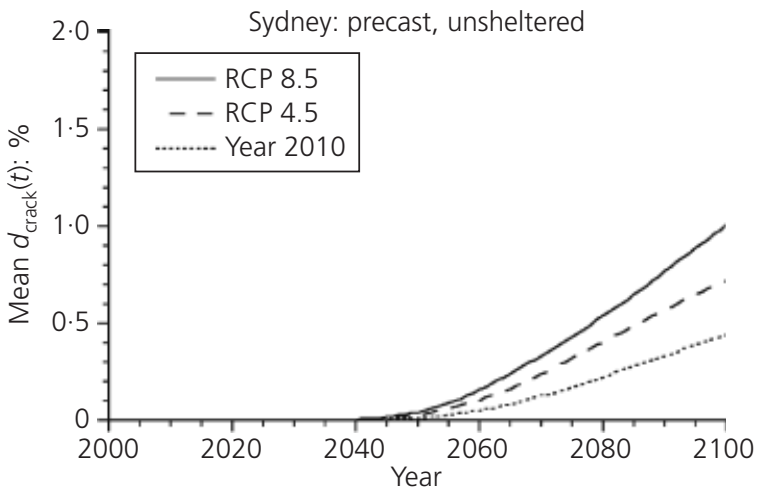

(d)

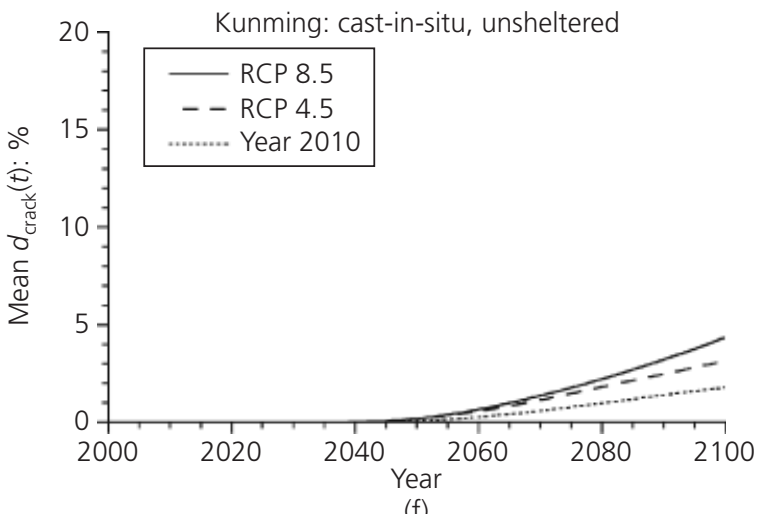

(f)

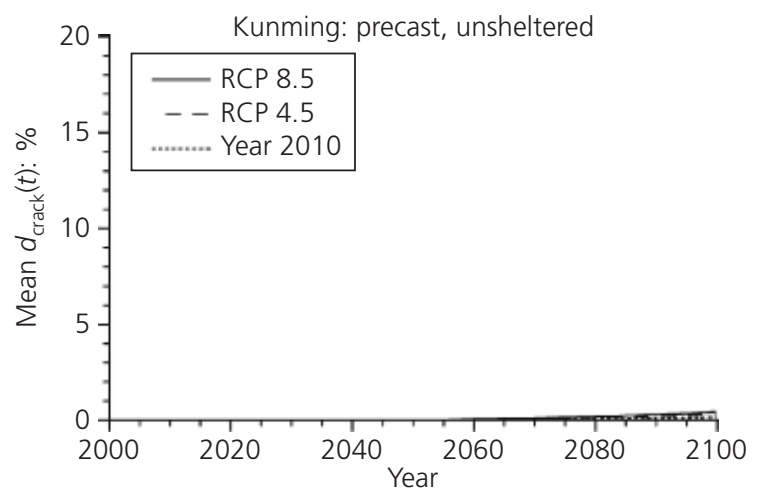

(h) 

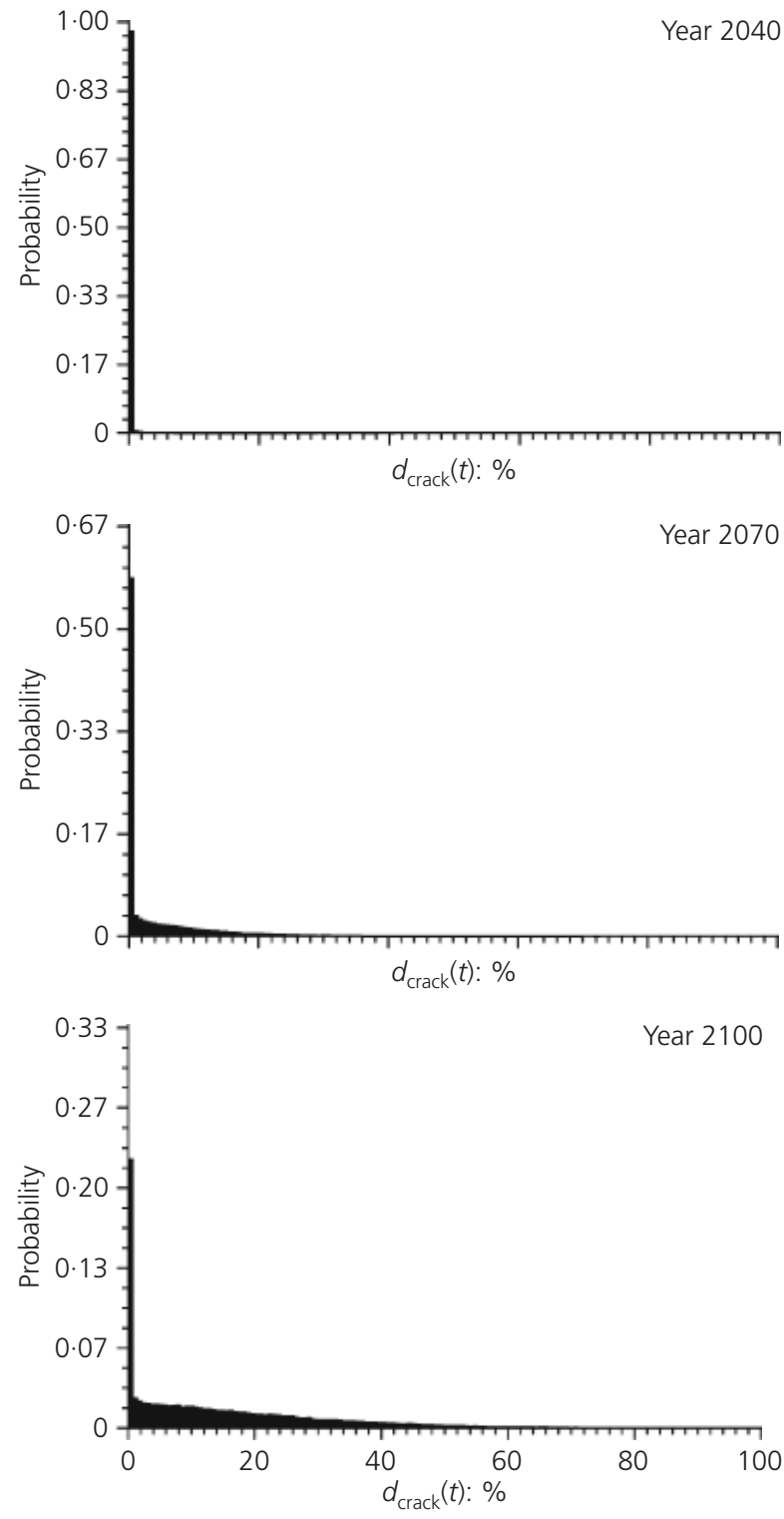

Figure 8. Simulation histogram of proportion of surface corrosion damage for cast-in-situ sheltered RC slabs in Kunming in 2040, 2070 and 2100 under RCP 4.5 emissions scenario

\section{Future work}

The analyses reported here are based on minimum concrete cover and concrete compressive strength from durability design specifications of AS 3600-2009 (Standards Australia, 2009) and GB 50010-2010 (MoCPRC, 2010) only. For a specific structure, accurate results about climate change impact and damage extent can be obtained only by considering structural typology, structural detailing and other structure-specific information. RC structures in areas that are more likely to suffer from decreasing durability as a consequence of climate change merit appropriate and costeffective adaptation measures. These may include an increase in design cover, an increase in concrete strength, the use of other types of concrete, an increase in concrete mix durability and the use of galvanised or stainless steel reinforcement and coatings.

Climate adaptation strategies aim to reduce the adverse impacts of climate change on RC infrastructure without increasing the environmental burden. Adaptation measures such as increased cement content may, however, lead to more carbon dioxide emissions since cement production is one of the biggest sources of emissions (Worrell et al., 2001). Another aspect that needs to be considered is the extra cost of adaptation; for instance, increasing cover thickness may increase the cost of forms, concrete, reinforcement, finishing and labour, as well as the structure's deadweight. Climate adaptation strategies including increased concrete cover, increased concrete strength, coatings, etc. have been discussed by Stewart et al. (2012), but more work is needed. Therefore, the efficiency and cost-benefit of adaptation measures are essential facets of further research.

Nevertheless, comparisons between predictions with experiments or in situ observations are necessary. The carbonation depths of existing buildings in some parts of China have been compared with predicted values. The results show that the predictions of carbonation models are $8 \%$ lower than actual measured data (Peng and Stewart, 2014), but more investigations are needed.

\section{Conclusions}

The paper has described a spatial time-dependent reliability analysis of the carbonation-induced corrosion deterioration of RC slabs under a changing climate. The spatial random fields of concrete cover, concrete strength, carbon dioxide diffusion coefficient and binding capacity are included while other material and corrosion parameters are treated as dependent spatial or random variables. Time-dependent carbon dioxide, temperature and $\mathrm{RH}$ effects on carbonation depth and corrosion rates are included. The results from the spatial time-dependent reliability analysis were presented in terms of likelihood and extent of surface corrosion damage for locations in Australia and China as well as different durability requirements, exposure conditions, emissions scenarios and construction methods. It was found that a changing climate could cause the extent of damage to increase by up to $6 \%$ for RC infrastructure in Kunming, China. The time of first repair could occur as soon as 2045 and 2050 for repair thresholds of $1 \%$ and $5 \%$ respectively. The presented findings could be used to develop climate adaptation measures in the design stage and cost-benefit analyses of climate adaptation measures.

\section{Acknowledgements}

The authors acknowledge the World Climate Research Programme's Working Group on Coupled Modelling, which is responsible for CMIP (coupled model intercomparison project), and thank the climate modelling groups (listed in Figures 1,2 and 3 of this paper) for producing and making available their model outputs. For CMIP, the US Department of Energy's Program for Climate Model Diagnosis and Intercomparison provided coordinating 

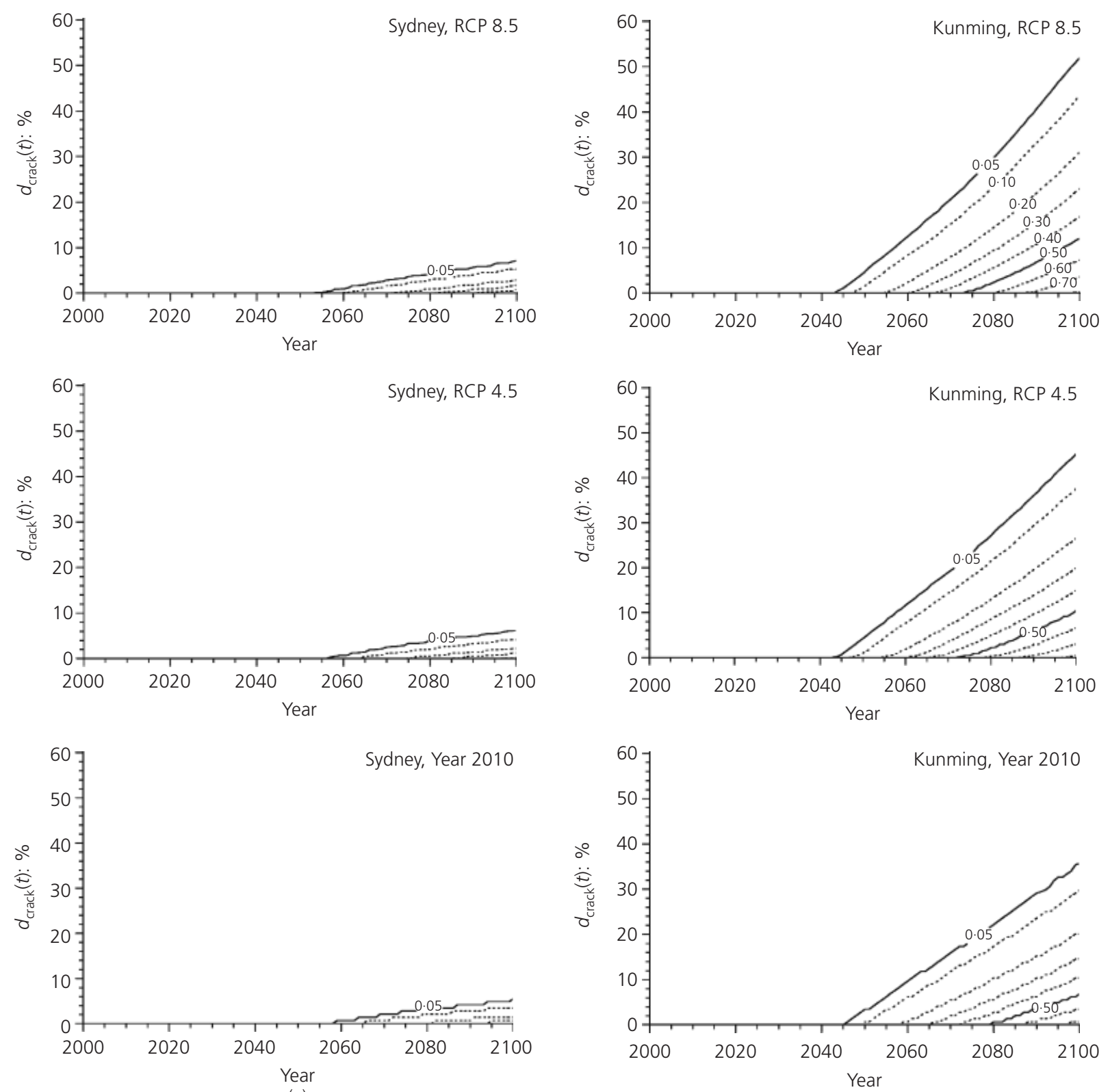

(a)

(b)

Figure 9. Probability contours for proportion of surface corrosion damage for cast-in-situ sheltered RC slabs under RCP 8.5, RCP 4.5 and year 2010 emissions scenarios for Sydney and Kunming

support and led the development of software infrastructure in partnership with the Global Organisation for Earth System Science Portals. The authors express their appreciation to Xiaoming Wang and Stacey Dravitzki of CSIRO for providing climate data for Australian and Chinese cities.

\section{REFERENCES}

Al-Harthy AS, Stewart MG and Mullard J (2011) Concrete cover cracking caused by steel reinforcement corrosion. Magazine of Concrete Research 63(9): 655-667.
Breysse D, Chaplain M and Marache A (2013) Simulation of synthetic climate at local scale as a mean to assess the impact of climate change on infrastructures. Proceedings of Safety, Reliability, Risk and Life-Cycle Performance of Structures and Infrastructures (ICOSSAR2013), New York, NY, USA. CRC Press, Boca Raton, FL, USA.

Chernin L, Val DV and Stewart MG (2012) Prediction of cover crack propagation in RC structures caused by corrosion. Magazine of Concrete Research 64(2): 95-111.

Darmawan MS and Stewart MG (2007) Spatial time-dependent 
reliability analysis of corroding pretensioned prestressed concrete bridge girders. Structural Safety 29(1): 16-31.

de Larrard F (1999) Concrete Mixture Proportioning: A Scientific Approach. Spon, London, UK.

Der Kiureghian A and Ke JB (1988) The stochastic finite element method in structural reliability. Probabilistic Engineering Mechanics 3(2): 83-91.

DuraCrete (1998) Modelling of Degradation, DuraCrete Probabilistic Performance Based Durability Design of Concrete Structures, EU - Brite EuRam III. European Union, Brussels, Belgium, Contract BRPR-CT95-0132, Project BE95-1347/R4-5.

DuraCrete (2000) Statistical Quantification of the Variables in the Limit State Functions. DuraCrete - Probabilistic Performance Based Durability Design of Concrete Structures, EU - Brite EuRam III. European Union, Brussels, Belgium, Contract BRPR-CT95-0132, Project BE95-1347/R9.

El Maaddawy T and Soudki KA (2007) A model for prediction of time from corrosion initiation to corrosion cracking. Cement and Concrete Composite 29(3): 168-175.

Fang C and Yang S (2011) Cracking characteristics of corroded $\mathrm{RC}$ beams under repeated loading. Magazine of Concrete Research 63(12): 941-952.

fib (Fédération internationale du béton) (2006) Model Code for Service Life Design. fib, Lausanne, Switzerland, Bulletin 34.

Foster S, Stewart MG, Loo M, Ahammed M and Sirivivatnanon V (2013) Calibration of reinforced concrete structures standard AS3600 part 1: statistical analysis of material properties and model error. Proceedings of Concrete 2013, Gold Coast, Australia, Paper 24.

Gonzalez JA, Algaba J and Andrade C (1980) Corrosion of reinforcing bars in carbonated concrete. British Corrosion Journal 15(3): 135-139.

Inman M (2011) Opening the future. Nature Climate Change 1(1): 7-9.

IPCC (Intergovernmental Panel on Climate Change) (2007) Fourth Assessment Report of the Intergovernmental Panel on Climate Change. Cambridge University Press, Cambridge, UK.

IPCC (2013) Climate Change 2013, The Physical Science Basis. Cambridge University Press, Cambridge, UK.

Kada-Benameur H, Wirquin E and Duthoit B (2000) Determination of apparent activation energy of concrete by isothermal calorimetry. Cement and Concrete Research 30(2): 301-305.

Li Y, Vrouwenvelder T, Wijnants G and Walraven J (2004) Spatial variability of concrete deterioration and repair strategies. Structural Concrete 5(3): 121-129.

Malumbela G, Moyo P and Alexander M (2011) Load-bearing capacity of corroded, patched and FRP-repaired RC beams. Magazine of Concrete Research 63(11): 797-812.

McGee R (1999) Modeling of durability performance of Tasmanian bridges. In ICASP8 Applications of Statistics and Probability in Civil Engineering (Melchers RE, Stewart MG (eds)). CRC Press, Balkema, the Netherlands.
Meinshausen M, Smith SJ, Calvin K et al. (2011) The RCP greenhouse gas concentrations and their extensions from 1765 to 2300. Climatic Change 109(1-2): 213-241.

Melchers RE, Li CQ and Lawanwisut W (2006) Modelling deterioration of structural behaviour of reinforced concrete beams under saline environment corrosion. Magazine of Concrete Research 58(9): 575-587.

Mirza SA and Hatzinikolas M (1979) Statistical descriptions of strength of concrete. Journal of the Structural Division, ASCE 105(6): 1021-1037.

MoCPRC (Ministry of Construction of the People's Republic of China) (2002) Code for design of concrete structures. MoCPRC, Beijing, China (in Chinese).

MoCPRC (2010) GB 50010-2010: Code for design of concrete structures. MoCPRC, Beijing, China (in Chinese).

Mullard JA and Stewart MG (2009) Stochastic assessment of timing and efficiency of maintenance for corroding RC structures. Journal of Structural Engineering 135(8): $887-$ 895.

Mullard JA and Stewart MG (2011) Corrosion-induced cover cracking: new test data and predictive models. ACI Structural Journal 108(1): 71-79.

Mullard JA and Stewart MG (2012) Life-cycle cost assessment of maintenance strategies for RC structures in chloride environments. Journal of Bridge Engineering 17(2): 353-362.

Na UJ, Kwon S, Chaudhuri SR and Shinozuka M (2012) Stochastic model for service life prediction of RC structures exposed to carbonation using random field simulation. KSCE Journal of Civil Engineering 16(1): 133-143.

Neville A (1995) Chloride attack of reinforced concrete: an overview. Materials and Structures 28(2): 63-70.

O'Connor A and Kenshel O (2013) Experimental evaluation of the scale of fluctuation for spatial variability modeling of chloride-induced reinforced concrete corrosion. Journal of Bridge Engineering 18(1): 3-14.

Papakonstantinou KG and Shinozuka M (2013) Probabilistic model for steel corrosion in reinforced concrete structures of large dimensions considering crack effects. Engineering Structures 57: 306-326.

Peng $L$ and Stewart MG (2014) Climate change and corrosion damage risks for reinforced concrete infrastructure in China. Structure and Infrastructure Engineering, 10.1080/ 15732479.2013.858270.

Peters GP, Andrew RM, Boden T et al. (2013) The challenge to keep global warming below $2^{\circ} \mathrm{C}$. Nature Climate Change $\mathbf{3}$ : 4-6.

Raupach M (2006) Models for the propagation phase of reinforcement corrosion - an overview. Materials and Corrosion 57(8): 605-613.

Reale T and O'Connor A (2012) A review and comparative analysis of corrosion-induced time to first crack models. Construction and Building Materials 36(1): 475-483.

RGRRCSM (Research Group on Reliability of Reinforced Concrete Structural Members) (1985) Investigation and statistical 
analysis of the dimensional tolerances of reinforced concrete structural members. Journal of Building Structures 6(4): 2-9 (in Chinese).

Richardson MG (1988) Carbonation of Reinforced Concrete: Its Causes and Management. Citis, Dublin, Ireland.

Rogelj J, Meinshausen M and Knutti R (2012) Global warming under old and new scenarios using IPCC climate sensitivity range estimates. Nature Climate Change 2(4): 248-253.

Roy S, Beng PK and Northwood D (1996) The carbonation of concrete structures in the tropical environment of Singapore and a comparison with published data for temperate climates. Magazine of Concrete Research 48(177): 293-300.

Russell D, Basheer PAM, Rankin GIB and Long AE (2001) Effect of relative humidity and air permeability on prediction of the rate of carbonation of concrete. Proceedings of the Institution of Civil Engineers - Structures and Buildings 146(3): 319326.

Shi Y and Stewart MG (2014) Spatial reliability analysis of explosive blast load damage to reinforced concrete columns. Structural Safety, in press.

Standards Australia (2004) AS 5100.5: Bridge design. Part 5: concrete. Standards Australia, Sydney, Australia.

Standards Australia (2009) AS 3600-2009: Concrete structures. Standards Australia, Sydney, Australia.

Sterritt G, Chryssanthopoulos MK and Shetty NK (2001) Reliability-based inspection planning for RC highway bridges. Safety and Risk in Engineering 32(10): 3279-3287.

Stewart MG (1996) Serviceability reliability analysis of reinforced concrete structures. Journal of Structural Engineering, ASCE 122(7): 794-803.

Stewart MG (2006) Spatial variability of damage and expected maintenance costs for deteriorating RC structures. Structure and Infrastructure Engineering 2(2): 79-90.

Stewart MG and Mullard JA (2007) Spatial time-dependent reliability analysis of corrosion damage and the timing of first repair for RC structures. Engineering Structures 29(7): $1457-$ 1464.

Stewart MG and Peng J (2010) Life cycle cost assessment of climate change adaptation measures to minimise carbonationinduced corrosion risks. International Journal of Engineering under Uncertainty: Hazards, Assessment and Mitigation 2(12): $35-46$.

Stewart MG, Wang XM and Nguyen MN (2011) Climate change impact and risks of concrete infrastructure deterioration. Engineering Structures 33(4): 1326-1337.

Stewart MG, Wang X and Nguyen MN (2012) Climate change adaptation for corrosion control of concrete infrastructure. Structural Safety 35: 29-39.

Sudret B (2008) Probabilistic models for the extent of damage in degrading reinforced concrete structures. Reliability Engineering and System Safety 93(3): 410-422.

Talukdar S, Banthia N, Grace JR and Cohen S (2012) Carbonation in concrete infrastructure in the context of global climate change: parts 1 and 2. Cement and Concrete Composites 34(8): 924-935.

Vanmarcke E (1983) Random Fields: Analysis and Synthesis. MIT Press, Cambridge, MA, USA.

Vu KAT and Stewart MG (2000) Structural reliability of concrete bridges including improved chloride-induced corrosion models. Structural Safety 22(4): 313-333.

Vu KAT and Stewart MG (2005) Predicting the likelihood and extent of reinforced concrete corrosion-induced cracking. Journal of Structural Engineering 131(11): 1681-1689.

Wang J and Qin Q (2007) Analysis of time-dependent reliability of RC highway bridges considering chloride attack and concrete carbonation. Engineering Mechanics 24(7): 94-101 (in Chinese).

Wiśniewski DF, Cruz PJS, Henriques AAR and Simões RAD (2012) Probabilistic models for mechanical properties of concrete, reinforcing steel and pre-stressing steel. Structure and Infrastructure Engineering 8(2): 111-123.

Worrell E, Price L, Martin N, Hendriks C and Meida LO (2001) Carbon dioxide emissions from the global cement industry 1. Annual Review of Energy and the Environment 26(1): 303-329.

Yoon IS, Copuroglu O and Park KB (2007) Effect of global climatic change on carbonation progress of concrete. Atmospheric Environment 41(34): 7274-7285.

Zhu W, Gibbs JC and Bartos PJM (2001) Uniformity of in situ properties of self-compacting concrete in full-scale structural elements. Cement and Concrete Composites 23(1): 57-64.

\section{WHAT DO YOU THINK?}

To discuss this paper, please submit up to 500 words to the editor at journals@ice.org.uk. Your contribution will be forwarded to the author(s) for a reply and, if considered appropriate by the editorial panel, will be published as a discussion in a future issue of the journal. 